\title{
A interação das cooperativas CRESOL e SICREDI com o centro de referência de assistência social: repercussões no desenvolvimento social e econômico do município de Cerro Largo/RS
}

The interaction of CRESOL and SICREDI cooperatives with the reference center for social assistance: repercussions on the social and economic $d$ of the municipality of Cerro Largo/RS

\section{Resumo}

O cooperativismo tem uma missão importante, estratégica e decisiva para liderar processos de desenvolvimento social e econômico, visando o bem-estar e a qualidade de vida dos envolvidos, tendo por base os fundamentos da participação democrática, solidariedade, independência e autonomia. Assim, a partir deste estudo, objetiva-se apresentar as contribuições geradas por uma parceria firmada entre as cooperativas de Crédito: Sistema de Crédito Rural (SICREDI) e a Cooperativa de Crédito Rural com Interação Solidária (CRESOL) com o Centro de Referência de Assistência Social (CRAS) Cerro Azul do Município de Cerro Largo/RS, Brasil. O trabalho classificase como um estudo descritivo, com abordagem qualitativa, e a coleta de dados ocorreu por meio de dados secundários e observação participante. Para a análise de dados, utilizou-se o programa LibreOffice Writer, versão 2010. Como resultado, percebeu-se que ambas as cooperativas colaboram com o público vinculado ao CRAS, seja com recursos financeiros e com apoio em ações e/ou projetos. Dessa forma, foi possível constatar que a parceria do CRAS com as referidas Cooperativas de Crédito contribui para o desenvolvimento social e econômico do município, além de demonstrar interesse na melhoria da qualidade de vida dos associados, bem como à comunidade em geral.

Palavras-chave: Projetos sociais, cooperativismo, economia solidária.

\begin{abstract}
Cooperativism has an important, strategic and decisive mission to lead social and economic development processes, aiming at the well-being and quality of life of those involved, based on the foundations of democratic participation, solidarity, independence and autonomy. Thus, from this study, the objective is to present the contributions generated by a partnership signed between Credit unions: Rural Credit System (SICREDI) and the Rural Credit Cooperative with Solidary Interaction (CRESOL) with the Assistance Reference Center Social (CRAS) Cerro Azul in the Municipality of Cerro Largo / RS, Brazil. The work is classified as a descriptive study, with a qualitative approach, and data collection occurred through secondary data and participant observation. For data analysis, the program LibreOffice Writer, version 2010 was used. As a result, it was noticed that both cooperatives collaborate with the public linked to CRAS, either with financial resources and with support in actions and / or projects. Thus, it was possible to verify that the CRAS partnership with the referred Credit Cooperatives contributes to the social and economic development of the municipality, in addition to showing interest in improving the quality of life of the members, as well as the community in general.
\end{abstract}

Keywords: Projects social, cooperativism, economy solidarity.

Fabiano Kapelinskil, Cláudia Jussara Harlos Heck ${ }^{\mathrm{II}}$, Carlos Eduardo Ruschel Anes ${ }^{\mathrm{III}}$, Enise Barth ${ }^{\mathrm{IV}}$, Louise de Lira Roedel Botelhov

I Universidade Federal da Fronteira Sul. fabianokapelinski@hotmail.com

II Universidade Federal da Fronteira Sul. claudia.harlos@hotmail.com

III Universidade Federal da Fronteira Sul. carlos.anes@uffs.edu.br

Iv Universidade Federal da Fronteira Sul. enise.teixeira@uffs.edu.br

v Universidade Federal da Fronteira Sul. louisebotelho@gmail.com 


\section{Introdução}

A exclusão social e econômica existente em nível mundial é um dos temas mais abordados por diversos setores da sociedade, por isso da relevância do estudo a fim de contribuir em paradigmas teóricos e em discussões desse problema central da sociedade contemporânea. À vista disso, o termo exclusão social passou a ser usado para explicar numerosos fenômenos sociais, podendo significar desde estar excluído da possibilidade de garantir a sobrevivência física, até um sentimento subjetivo de ressentimento por não desfrutar de bens, capacidades ou oportunidades que outros indivíduos desfrutam (DUPAS, 1999).

Para Lourenço (2005) apesar do crescimento econômico significativo a que se tem assistido nos últimos séculos, não se verifica a redução automática de problemas sociais. 0 autor enfatiza que a exclusão social tem se agravado nas últimas décadas, para além do alargamento das desigualdades entre os países, entre as classes sociais e entre os indivíduos.

Exclusão social constitui, sobretudo, um dos maiores desafios do nosso século, na medida em que colide com o exercício dos direitos fundamentais dos seres humanos (TAVARES, 2013). Diante disso, os 17 Objetivos de Desenvolvimento Sustentável (ODS) da Agenda 2030, vem com o propósito de afrontar problemas sociais, são um plano de ação para as pessoas e para o planeta, que busca alcançar prosperidade e fortalecer a paz universal para erradicar a pobreza e promover vida digna para todos, dentro dos limites do planeta (PLATAFORMA AGENDA 2030, 2018).

Nesse sentido, com o intuito de uma reação e afrontamento aos problemas sociais, à exclusão social, às desigualdades sociais, vislumbrou-se a necessidade de constituir possibilidades viáveis para a organização e sobrevivência dos indivíduos. De acordo com Santos (2012), tais possibilidades denominadas "alternativas", são opções econômicas ao capitalismo. Surgindo como meios de resistirem à hegemonia capitalista, não rejeitam o crescimento econômico, mas impõem limites a ele. Neste trabalho, destacam-se como alternativas à concepção de economia solidária e o cooperativismo.

Nesse contexto, abrange o termo economia solidária, pois embarca em atividades de cooperação mútua, em um modo de produção e de distribuição alternativo ao capitalismo, como um instrumento de transformação social. Desse modo, a economia solidária é uma maneira de organizar as atividades econômicas de determinado lugar. Em vez da liberdade absoluta proposta pelo capitalismo de mercado, as associações são feitas de maneira mais padronizada, buscando diminuir a desigualdade de ganhos (SINGER, 2002).

A economia solidária surge como uma estratégia para um novo modelo de desenvolvimento sustentável, includente e solidário, visto que todos os envolvidos se beneficiam dos seus resultados econômicos, sociais, políticos e culturais. Essa noção é reforçada quando se percebe que não há qualquer tipo de discriminação entre os envolvidos, havendo respeito pela raça, etnia, gênero, geração e opção religiosa (SILVA, 2008).

O cooperativismo se baseia no coletivo, na cooperação como uma nova forma de organização, que proporcionaria a seus integrantes melhor qualidade de vida (KEIL; MONTEIRO, 1982). De modo geral, tem uma missão importante, estratégica e decisiva para liderar os processos de desenvolvimento de uma nação e de um território, mediante a articulação qualificada com as demais instituições e organizações produtivas, econômicas e sociais (MASY, 1992). O cooperativismo é considerado, portanto, um movimento de organização moldado conforme sua constituição de 
estrutura social e econômica, concepção política e crenças religiosas, as quais variam de acordo com o problema a ser superado (FRANTZ, 2012).

Diante do exposto, pretende-se apresentar as contribuições geradas a partir de uma parceria firmada entre as cooperativas de Crédito SICREDI e CRESOL e o Centro de Referência de Assistência Social (CRAS) Cerro Azul do Município de Cerro Largo/RS, no intuito de ambas colaborarem por meio de ações realizadas pelos projetos que integram o Serviço de Proteção e Atendimento Integral à Família (PAIF), como uma possibilidade de fortalecimento das capacidades individuais e coletivas dos participantes, buscando oferecer qualificação profissional, preparo para o mercado de trabalho e geração de renda, resultando em autonomia e segurança. Essa ação estende-se também a projetos disponibilizados mediante o Programa de Serviço de Convivência e Fortalecimento de Vínculos (SCFV), que tem caráter preventivo e objetiva complementar o trabalho social com as famílias atendidas.

Referidos projetos oferecidos no CRAS Cerro Azul são destinados aos usuários do Sistema Único de Assistência Social, preferencialmente a cidadãos de baixa renda inscritos no CadÚnico, beneficiários do Programa Bolsa Família, cidadãos que recebem Benefício de Prestação Continuada e trabalhadores da Cooperativa de Trabalho de Catadores Unidos pela Natureza (COOPERCAUN). Além dos citados, há grupos de mulheres da Zona Rural do município de Cerro Largo, membros de Clubes de Mães que participaram de cursos do Serviço Nacional de Aprendizagem Rural (SENAR), que também foram receptores de benefícios oriundos dessa parceria.

No que diz respeito à estrutura deste artigo, depois desta parte introdutória, abordam-se os procedimentos metodológicos, dissertando sobre abordagem, objetivo, procedimentos, coleta de dados e público-alvo. Na sequência, descrevem-se concepções sobre desenvolvimento social e econômico. Após, expõem-se as alternativas de sobrevivência, economia solidária e cooperativismo e, por conseguinte, aspectos relevantes do cooperativismo de crédito e do Centro de Referência de Assistência Social (CRAS). Por fim, apresentam-se a discussão dos resultados, e as considerações finais do texto, tecidas no intuito, não de concluir, mas de contribuir para um debate contínuo e fértil e que possa auxiliar na compreensão do estudo.

\section{Procedimentos Metodológicos}

Este estudo apresenta uma abordagem qualitativa, voltada à produção de dados descritivos, por meio das informações apresentadas pelos investigados e da conduta observada. Consiste, sim, em interpretar e compreender, com base em um olhar imparcial de pesquisador, a totalidade do ambiente em que se apresenta o objeto de estudo (TAYLOR; BOGDAN, 1998).

Quanto aos objetivos, trata-se de um artigo descritivo, pois buscou-se descrever os resultados gerados a partir de uma parceria firmada com as cooperativas de Crédito SICREDI e CRESOL com o CRAS Cerro Azul do município de Cerro Largo/RS. Estudos descritivos, segundo afirma Gil (2002), apresentam como objetivo essencial a descrição de características do objeto de estudo, ou o estabelecimento de relações entre as variáveis.

Quanto aos procedimentos, classifica-se como um artigo de caráter documental. Para tanto, recorreu-se a fontes mais diversificadas e dispersas, sem tratamento analítico, tais como: relatórios, documentos oficiais, artigos, documentários, fotografias, tudo isso disponibilizado pelo CRAS do município de Cerro Largo/RS. Além disso, salienta-se que foram realizadas observações participantes para o atingimento do que foi proposto. 
Em relação à coleta de dados, esta foi realizada a partir de dados secundários que Matar (2005) define como fontes de dados indiretos e que estão à disposição para consulta. Esses dados foram obtidos por meio de relatórios e documentos disponibilizados pelo CRAS, bem como se utilizaram livros e outros materiais, tais como artigos científicos, dissertações e teses relacionadas às temáticas centrais como exclusão social, economia solidária, desenvolvimento social e econômico.

0 artigo de experiência está voltado para trabalhadores do meio rural, desempregados, catadores de materiais recicláveis, ou inseridos na informalidade, beneficiários do CadÚnico, do Programa Bolsa Família, e membros de Clubes de Mães que participaram de cursos do SENAR.

Desse modo, salienta-se que a taxa de desocupados em relação à população ativa de Cerro Largo e região é de 3,58\%. A população do meio rural corresponde a 2718 pessoas. Em termos de trabalho e renda, a região de Cerro Largo apresenta 15,71\% de vulneráveis na pobreza; além disso, 37,33\% das pessoas com dezoito anos ou mais sem ensino fundamental completo estão em ocupação informal. E registrado no CadÚnico tem-se o número de 5.111 pessoas. Assim, do total de 13.289 habitantes da região de Cerro Largo, de 10 a 20\% estão enquadrados como habitantes do meio rural, desempregados, inseridos na informalidade e integrantes do CadÚnico (Instituto Brasileiro de Geografia e Estatística [IBGE], 2013).

Diante desse contexto, destaca-se que o município de Cerro Largo/RS se localiza na região das Missões do Estado do Rio Grande do Sul, com origem no processo de colonização, e fundação ocorrida em 4 de outubro de 1902, em terras férteis e cobertas de mata virgem, entre os rios Ijuí e Comandaí, a Colônia Serro Azul. Além disso, o município é conhecido como Berço Regional da Cultura, cognome que lhe foi conferido porque, desde o início da colonização, se destacou pelo número e qualidade educativa (Instituto Brasileiro de Geografia e Estatística [IBGE], 2017).

\section{Desenvolvimento Social e Econômico}

O Desenvolvimento trouxe uma nova maneira de a sociedade entender os processos de mudança social. Desse modo, entender o desenvolvimento não se trata somente de uma questão conceitual, mas de postura e de sentimento, basicamente sustentados pela modéstia e promotores da simplicidade. A dimensão humana do desenvolvimento está centrada fundamentalmente na valorização das pessoas em sua plenitude, que supõe crescimento econômico não como fim, mas como meio de reduzir as privações e as aflições humanas (TORRAS; ALMANSA, 1995).

Desse modo, o desenvolvimento é caracterizado por transformações qualitativas no modo de vida das pessoas, nas instituições e nas estruturas produtivas, como também por um processo complexo de mudanças de ordem econômica, política e, principalmente, humana e social. Essa mudança busca satisfazer as mais diversificadas necessidades do ser humano, tais como: saúde, educação, habitação, transporte, alimentação, lazer, dentre outras (DE OLIVEIRA, 2002).

Nesse sentido, o desenvolvimento social refere-se à melhoria da qualidade de vida da população. Para o caso de países com problemas de desigualdade e de inclusão social, implica a adoção de políticas distributivas e a universalização de atendimento a questões como saúde, educação, habitação e seguridade social (SACHS, 1993). Em vista disso, o termo desenvolvimento social se refere à circunstância na qual a sociedade adquire melhores condições de vida de maneira sustentável.

Furtado (1977), um dos principais pensadores dessa construção teórica, salienta que o desenvolvimento social, nas décadas de 1950 e 1960, na América Latina, estava assentado na 
convicção da necessidade de transformação daqueles elementos estruturais que mais obstavam toda e qualquer mudança. Dessa forma, compreende-se que o conceito de desenvolvimento social, na obra de Celso Furtado, se caracteriza por defender uma transformação profunda da sociedade. Esse estudioso diz: "Utilizo a palavra transformação para significar desenvolvimento global, o que inclui mudanças ao nível das estruturas" (FURTADO, 1977, p. 126).

Segundo Elias (1999), o desenvolvimento social caracteriza-se por ser um processo de subsidiar o rendimento da maioria, e não o aumento da riqueza de um grupo de pessoas. Tem por objetivo aliviar a pobreza do povo, contribuir para melhoria do bem-estar social, a distribuição de rendas, a ampliação dos espaços políticos e de democratização e o fortalecimento do papel do Estado na formulação de políticas distributivas e sociais. São, para isso, necessárias medidas decisivas para regular a produtividade e o rendimento dos indivíduos politicamente integrados num estado particular (ELIAS, 1999).

Enquanto isso, o desenvolvimento econômico pode ser entendido como um processo sistemático e histórico de crescimento sustentado da renda ou do valor adicionado por habitante, acarretando melhoria de salários e padrões de bem-estar de vida de determinada sociedade que, por vezes, resulta da sistemática acumulação de capital e da incorporação de conhecimento ou progresso técnico à produção (FURTADO, 1977; BRESSER PEREIRA, 2008). Dessa forma, pode-se afirmar que o desenvolvimento econômico é um processo de transformação que provoca modificações em três principais instâncias de uma sociedade: estrutural, institucional e cultural (BRESSER PEREIRA, 2006).

Alinhado a esse argumento, Bresser Pereira (2006) defende que, para promover o desenvolvimento econômico nas instâncias estruturais, institucionais e culturais de uma sociedade, é essencial que as instituições garantam estabilidade política, condições de funcionamento do mercado, oportunidades de lucro e que estimulem os empresários ao investimento. Não obstante, o autor frisa que é fundamental que o Estado, na sua qualidade de instituição maior, seja eficiente, tenha legitimidade e capacidade para formular políticas públicas e sociais, cobrar impostos e impor leis adequadas às necessidades da sociedade.

Sandroni (1994) considera que o desenvolvimento econômico é acompanhado por melhorias do nível de vida dos cidadãos e por alterações estruturais na economia. Além disso, defende que o desenvolvimento depende das características de cada país ou região. Isto é, depende do seu passado histórico, da posição e extensão geográficas, das condições demográficas, da cultura e dos recursos naturais que possuem.

Portanto, o desenvolvimento social está relacionado ao desenvolvimento econômico na medida em que uma melhor situação de vida pode ser oferecida à população por meio de melhores acessos aos bens e serviços.

\section{Economia Solidária e Cooperativismo}

A expressão "Economia Solidária" (ES) foi usada de modo pioneiro no Brasil, em 1996, por Paul Singer, em um artigo intitulado "Economia Solidária contra o Desemprego". Nesse sentido, quando se trata da construção do movimento da Economia Solidária, lutas históricas dos trabalhadores, e movimentos sociais frente aos processos de exclusão e exploração social, como alternativa ao modo capitalista de organizar as relações sociais dos seres humanos entre si e destes com a natureza, constituem-se como base de sua proposta fundante (SINGER, 2000). 
De acordo com a Central de Cooperativas e Empreendimentos Solidários - UNISOL - Brasil (2010), a Economia Solidária trata-se de um modo específico de produção, distribuição, comercialização e operacionalização de crédito, baseado na posse coletiva dos meios e/ou empreendimentos, os quais tem sua gestão democrática e participativa, com distribuição das sobras e perdas de modo igualitário. Desta forma, a Economia Solidária mostra-se como forma alternativa de trabalho renda para pessoas com dificuldade de adaptação às regras existentes, favorecendo a inclusão social.

A economia solidária é uma forma de economia que cada vez mais se difunde. Estudiosos da área a conceituam como uma possibilidade para a criação de um novo modelo econômico, voltado principalmente para o coletivo. Para Singer (2000), a Economia Solidária nasceu na Europa, na época do capitalismo industrial, como uma forma de defesa dos trabalhadores. Isso se deu em função da troca destes por máquinas, as quais realizavam o trabalho de forma mais eficiente. Em suas palavras, Singer e Souza (2000) destacam:

\begin{abstract}
A economia solidária surge como um modo de produção e distribuição alternativo ao capitalismo, criado e recriado periodicamente pelos que se encontram (ou temem ficar) marginalizados do mercado de trabalho. A economia solidária casa o princípio da unidade entre a posse e uso dos meios de produção e distribuição (da produção simples de mercadorias) com o princípio da socialização destes meios (do capitalismo). A economia solidária não é criação intelectual de alguém, embora os grandes autores socialistas denominados utópicos da primeira metade do século XIX (Owen, Fourier, Buchez, Proudhon, etc.) tenham dado contribuições decisivas ao seu desenvolvimento (SINGER e SOUZA, 2000, p. 13).
\end{abstract}

Para Pedrini e Oliveira (2007), a economia solidária é um movimento que procura organizar a economia popular garantindo o bem-estar das pessoas e não apenas o lucro. Dessa forma, seria uma alternativa para os momentos de crises trabalhistas e está historicamente baseada na solidariedade dos povos e em suas lutas por emancipação no decorrer dos anos.

A economia solidária é, ainda, uma atividade econômica e social organizada em cooperativas, associações e outras organizações, as quais produzem bens e serviços com o objetivo do consumo solidário entre os associados. Compreende uma diversidade de práticas econômicas e sociais organizadas sob a forma de cooperativas, associações, clubes de troca, empresas autogestionárias, e redes de cooperação, dentre outras, que realizam atividades de produção de bens, prestação de serviços, finanças solidárias, trocas, comércio justo e consumo solidário (MINISTÉRIO DO TRABALHO E EMPREGO, 2014).

Para além do aspecto econômico financeiro, a Economia Solidária mostra-se como um modo de pensar que favorece a coletividade em face dos interesses individuais. Uma vez que, não há a figura representativa de um patrão nestes empreendimentos, que são afirmados pela autogestão, bem como as práticas do trabalho solidário são capazes de melhorar a condição humana do grupo, permitindo a valorização quanto coletividade por meio da colaboração recíproca e do aprendizado (UNISOL, 2010).

A Economia Solidária representa práticas fundadas em relações de colaboração solidária, inspiradas por valores culturais que colocam o ser humano como sujeito e finalidade da atividade econômica, ao contrário da acumulação privada de riqueza em geral e de capital em particular. É um poderoso instrumento de combate à exclusão social, e se apresenta como alternativa viável para a geração de trabalho e renda, constatando que é possível organizar a produção e a reprodução da sociedade de modo a eliminar as desigualdades materiais e sociais e difundir os valores da 
solidariedade humana, qualidade de vida e desenvolvimento sustentável, constituído com base em outra economia, a "Economia Solidária" (FBES, 2006).

Dessa forma, verificou-se que o conceito de economia solidária é amplo e ainda precisa de estudos aprofundados para que venha a ser mais disseminado na sociedade. Mesmo com pequenas diferenças, a principal característica citada pelos estudiosos é que a economia solidária se centra no trabalho coletivo para que consiga se estabelecer em determinado ambiente, tornando-se uma nova forma de organização como cooperativas ou associações. Torna-se um novo modo de produção e distribuição de renda mais igualitário, que permitirá melhoria nas condições de vida de seus associados ou cooperados.

A natureza cooperativa traz em seu âmago o princípio da solidariedade. Esse instinto de ajuda mútua atravessa a existência dos seres vivos. Hábitos de solidariedade e apoio recíproco têm garantido a sobrevivência das espécies ao longo dos tempos. São clássicos os exemplos da formiga precavida e laboriosa e da abelha ativa, símbolos do espírito de associação, de serviço em causa comum. São conhecidas as suas admiráveis organizações de defesa e apoio mútuo, tanto na paz como na guerra. Também entre os pássaros, como bem frisam os naturalistas e ecólogos, é frequente esse espírito de coesão e de cooperação na luta em comum pela sobrevivência. Essas operações são incessantes. A natureza trabalha segundo o princípio 'todos por um por todos'. A pressão exercida sobre um ponto repercute em cada uma das arcadas e em cada um dos fundamentos do edifício. Há nela uma solidariedade perfeita. Esse princípio, essa solidariedade que existem na ordem da natureza têm por instrumento específico a cooperação (KLAES, 2006).

Além de o cooperativismo tratar a solidariedade e garantir a sobrevivência das espécies, a natureza cooperativa atua também no ser humano. Assim, o cooperativismo está relacionado com a integração das pessoas que possuem objetivos em comum, na busca por um desenvolvimento coletivo, o que proporciona melhor resultado. A palavra cooperativismo origina-se da palavra cooperação e apresenta-se como doutrina de caráter cultural, porém refletida ao âmbito socioeconômico dos indivíduos envolvidos, pois estabelece a valorização da liberdade humana desenvolvida por fundamentos utilizados como princípio doutrinários (ALEIXO et al., 2015).

As cooperativas nascem de uma relação social, com objetivos econômicos, que possuem sentido mais amplo que sua dimensão econômica (FRANTZ, 2012). Elas são associações autônomas formadas por pessoas que se unem voluntariamente para satisfazer suas aspirações sociais, econômicas e culturais (SCHMIDT; PERIUS, 2003). Assim, Frantz (2012) descreve que cooperativas são associações de pessoas (projeto social) e entidades econômicas (projeto econômico), se diferenciando, por tal motivo, das demais sociedades, complementam Schmidt e Perius (2003).

As primeiras experiências que envolvem relações cooperativas contínuas e organizadas originam-se de um movimento europeu em meados dos anos 1800 (KLAES, 2006). A partir deste contexto tem-se um desenvolvimento de tradições cooperativistas que necessitam ser compreendidas para a noção da evolução da humanidade, tornando-se um movimento mundial.

O cooperativismo teve origem em características específicas advindas do capitalismo industrial, dentre as quais o individualismo das pessoas. 0 cooperativismo baseia-se no coletivo, na cooperação como uma nova forma de organização, que proporcionaria a seus integrantes melhor qualidade de vida. A primeira iniciativa que envolveu o cooperativismo foi a Sociedade dos Probos de Rochdale, em 1844, na cidade inglesa de Manchester (KEIL; MONTEIRO, 1982). 
Os princípios norteadores do movimento cooperativista estão organizados em sete regras básicas:

Os sete princípios do cooperativismo:

1. Adesão voluntária e livre: As cooperativas são organizações voluntárias, abertas a todas as pessoas aptas a utilizar os seus serviços e a assumir as responsabilidades como membros, sem discriminações de sexo, sociais, raciais, políticas e religiosas.

2. Gestão democrática e livre: As cooperativas são organizações democráticas, controladas pelos seus membros, que participam ativamente na formulação das suas políticas e na tomada de decisões. Os homens e as mulheres, eleitos como representantes dos demais membros, são responsáveis perante estes. Nas cooperativas de primeiro grau, os membros têm igual direito de voto (um membro, um voto); as cooperativas de grau superior são também organizadas de maneira democrática.

3. Participação econômica dos membros: Os membros contribuem equitativamente para o capital das cooperativas e controlam-no democraticamente. Parte desse capital é, normalmente, propriedade comum da cooperativa. Os membros recebem, habitualmente, se houver, uma remuneração limitada ao capital integralizado, como condição de sua adesão. E destinam os excedentes a uma ou mais das seguintes finalidades: Desenvolvimento das suas cooperativas, eventualmente através da criação de reservas, parte das quais, pelo menos uma, será indivisível, benefício aos membros na proporção das suas transações com a cooperativa, apoio a outras atividades aprovadas pelos membros.

4. Autonomia e independência: As cooperativas são organizações autônomas, de ajuda mútua, controladas pelos seus membros. Se firmarem acordos com outras organizações, incluindo instituições públicas, ou recorrerem a capital externo, devem fazê-lo em condições que assegurem o controle democrático pelos seus membros e mantenham a autonomia da cooperativa.

5. Educação, formação e informação: As cooperativas promovem a educação e a formação dos seus membros, dos representantes eleitos e dos trabalhadores, de forma que estes possam contribuir, eficazmente, para o desenvolvimento das suas cooperativas. Informam o público em geral, particularmente os jovens e os líderes de opinião, sobre a natureza e as vantagens da cooperação.

6. Intercooperação: As cooperativas servem de forma mais eficaz os seus membros e dão mais força ao movimento cooperativo, trabalhando em conjunto, através das estruturas locais, regionais, nacionais e internacionais.

7. Interesse pela comunidade: As cooperativas trabalham para o desenvolvimento sustentado das suas comunidades através de políticas aprovadas pelos membros (ETGETO, et al. 2005, p. 10).

Por meio destes princípios, o cooperativismo se tornou um modelo de organização, atuando de modo norteador do movimento cooperativista e contribuindo como afirmativa para o desenvolvimento de uma sociedade igualitária e justa. Isso se justifica pela identificação de pontos em comum com a concepção inicial de cooperação, concebidos mediante a integração dos indivíduos, tanto por meio da relação entre trabalho e capital, como também pela valorização do fator social, proporcionando maior participação do cooperados na gestão do empreendimento e na divisão dos lucros (CRUZIÓ, 2005).

Por causa disso, existem numerosos aspectos que devem ser considerados antes de tentar elaborar um conceito concreto sobre as cooperativas. Pode-se entender que são sociedades de pessoas, organizadas em busca da satisfação de necessidades e objetivos comuns. Além disso, a gestão dessas organizações apresenta certas peculiaridades relacionadas tanto com a estrutura organizacional diferenciada, como com as questões relativas às ações coletivas e à participação (RIGO et al., 2010).

No Brasil, a Organização das Cooperativas Brasileiras (OCB) é responsável pelo fomento e defesa do sistema cooperativista no Brasil, de modo a proporcionar soluções mais justas e 
equilibradas, melhorando oportunidades para todas as pessoas. A OCB define que o cooperativismo ultrapassa um modelo de negócios, mostrando-se como uma filosofia de vida capaz de conciliar o desenvolvimento econômico e social, produtividade e sustentabilidade (OCB, 2019).

Compreende-se que o cooperativismo não é um movimento de estruturação única. Pode ser considerado um movimento de organização moldado conforme sua constituição de estrutura social e econômica, concepção política e crenças religiosas (FRANTZ, 2012). Cada movimento possui diferentes interpretações de cooperativismo e propostas diversas, as quais variam de acordo com o problema a ser superado.

Portanto, a origem das cooperativas tem grande relação com a história do movimento cooperativista, e são fundamentadas pelos princípios do cooperativismo. Há um ramo do cooperativismo que trabalha com as chamadas cooperativas de créditos. Essas organizações são instituições financeiras criadas para oferecer soluções aos seus associados, constituindo-se num instrumento para acesso a produtos e serviços adaptados às suas necessidades. Essas instituições têm como princípios fundamentais a união por adesão voluntária e livre, gestão democrática, participação econômica dos membros, autonomia e independência (PINHEIRO, 2008).

As "cooperativas de crédito são sociedades de pessoas, constituídas com o objetivo de prestar serviços financeiros aos seus associados, na forma de ajuda mútua, baseada em valores como igualdade, equidade, solidariedade, democracia e responsabilidade social" (PAGNUSSATT, 2004: 13). Além da prestação de serviços comuns, visam a diminuir desigualdades sociais, facilitar o acesso aos serviços financeiros, difundir o espírito da cooperação e estimular a união de todos em prol do bemestar comum (PAGNUSSATT, 2004).

Neste trabalho, trata-se de apresentar as contribuições de duas cooperativas de créditos com o CRAS. Dessa forma, abordam-se concepções da SICREDI e da CRESOL. A SICREDI é um sistema de três níveis formado por cento e dezesseis cooperativas singulares filiadas, e cinco centrais regionais, acionistas da Sicredi Participações S.A., uma confederação, uma fundação e um banco cooperativo e suas empresas controladas. Todas essas entidades adotam um padrão operacional único. A atuação em sistema permite ganhos de escala e aumenta o potencial das cooperativas financeiras para exercer a atividade em um mercado no qual estão presentes grandes conglomerados financeiros (FUNDAÇÃO SICREDI, 2019).

A CRESOL é uma rede de cooperativas de crédito rural com interação solidária, que busca promover a inclusão social de agricultores familiares, ao facilitar o acesso a produtos e a serviços financeiros. Foi criada com a missão de atuar no fortalecimento e no estímulo da interação solidária entre os agricultores e suas organizações, por meio do crédito e da apropriação de conhecimento, visando ao desenvolvimento local com sustentabilidade (CRESOL, 2019).

Em vista disso, as cooperativas de crédito exerceram um papel de agentes de desenvolvimento econômico e social, além de colocar a moeda em circulação, cumprindo uma de suas principais funções na economia (FUNDAÇÃO SICREDI, 2014). No entanto, as cooperativas só conseguem promover o desenvolvimento, quando possuem uma gestão executiva que tenha foco na eficiência econômica e uma gestão social. É preciso também que essa gestão se preocupe em atender a real necessidade de cada associado, para que todos cresçam, gerem renda e serviços. Com isso, originam empregos e conseguem tirar alguns indivíduos das condições subumanas de vida, da exclusão social, para que se reintegrem na sociedade (SANTANA, 2010). 
Desse modo, o cooperativismo de crédito é de singular importância para a sociedade, na medida em que promove a aplicação de recursos privados e assume os correspondentes riscos em favor da própria comunidade onde se desenvolve. Dessa forma, por representar iniciativas dos próprios cidadãos, contribui de forma relevante para o desenvolvimento sustentável, especialmente nos aspectos de formação de poupança e de financiamento de iniciativas empresariais que trazem benefícios evidentes em termos de geração de empregos e de distribuição de renda (SOARES; SOBRINHO, 2008).

Portanto, o cooperativismo tem uma missão importante, estratégica e decisiva para liderar os processos de desenvolvimento de uma nação e um território (MASY, 1992). Essa missão deve ser cumprida não de maneira solitária, mas em articulação qualificada com as demais instituições e organizações produtivas, econômicas e sociais. A literatura corrente tem demonstrado que os países desenvolvidos, com melhores indicadores socioeconômicos, político-culturais e ambientais, alcançaram esse patamar por meio da ação coordenada e articulada entre os diferentes atores que interagem no território (BÜTTENBENDER, 2010).

\section{Centro de Referência de Assistência Social (CRAS)}

O CRAS foi implantado no município de Cerro Largo/RS no ano de 2010 com o nome de CRAS Cerro Azul. Inicialmente, esse setor integrava a já extinta Secretaria de Saúde e Bem-Estar Social. Porém, mediante a Lei no 2.706, de 6 de setembro de 2017, criou-se a Secretaria de Trabalho e Assistência Social. Além dessa Secretária dispor de um Centro de Referência de Assistência Social (CRAS), possui um Centro de Referência Especializado de Assistência Social (CREAS), um Setor de Atendimento do Cadastro Único, Programa Bolsa Família, Carteira do Idoso/Benefício de Prestação Continuada e Benefícios Eventuais e Gestão. De acordo com o que consta na Constituição Federal de 1988 (artigos 203 e 204), a Política de Assistência Social é direito de todo cidadão que dela necessitar (BRASIL, 1988; LEI no 2.711, 2017).

Nesse sentido, o CRAS é uma unidade de Proteção Social Básica do SUAS (Sistema Único de Assistência Social), que tem por objetivo prevenir a ocorrência de situações de vulnerabilidades e riscos sociais nas áreas de abrangência. É o principal equipamento de desenvolvimento dos serviços socioassistenciais da proteção social básica. Constitui espaço de concretização dos direitos socioassistenciais nos territórios, materializando a política de assistência social (TÉCNICAS, 2009).

O CRAS é uma unidade pública estatal descentralizada da política de assistência social, responsável pela organização e oferta de serviços da proteção social básica do Sistema Único de Assistência Social (SUAS) nas áreas de vulnerabilidade e risco social dos municípios e DF. Dada sua capilaridade nos territórios, se caracteriza como a principal porta de entrada do SUAS, ou seja, é uma unidade que possibilita o acesso de um grande número de famílias à rede de proteção social de assistência social (TÉCNICAS, 2009, p.11).

O espaço é responsável pela gestão da proteção básica no seu território e pela oferta do Serviço de Proteção e Atendimento Integral à Família (PAIF), além da responsabilidade pela integração dos demais serviços e benefícios socioassistenciais. 0 público-alvo atendido são famílias e indivíduos em situação de vulnerabilidade e riscos sociais (TÉCNICAS, 2009).

O CRAS é uma unidade da rede socioassistencial de proteção social básica que se diferencia das demais, além da oferta de serviços e ações, possui as funções exclusivas de oferta pública do trabalho social com famílias do PAIF e de gestão territorial da rede socioassistencial de proteção social básica. Porém, a oferta dos serviços no CRAS deve ser planejada e depende de um bom conhecimento do 
território e das famílias que nele vivem suas necessidades, potencialidades, bem como do mapeamento da ocorrência das situações de risco e de vulnerabilidade social e das ofertas já existentes (TÉCNICAS, 2009).

Para Castro (2009), o CRAS é o local de referência para a população, para dar conta de seu papel. No que se refere ao aspecto logístico, deve ter localização adequada, visibilidade pública e acessibilidade. Deve ainda considerar os aspectos históricos e culturais da população que vive no território, possibilitando a apropriação dessa unidade pelos seus usuários, que a percebam como patrimônio da comunidade.

Por fim, Rochemback (2017) ressalta que o CRAS contribui para o desenvolvimento de sujeitos autônomos e protagonistas de sua história, capazes de transpor por conta própria as dificuldades da sua vida. Com a implantação dos Centros de Referência nos municípios, a política de assistência social tornou-se mais visível e a oferta dos serviços se desvincula do favorecimento político e torna-se acessível a todos os cidadãos, em local de fácil ingresso, onde a acolhida e a escuta respeitosa estão asseguradas.

\section{Discussão dos Resultados}

Desde o início do ano de 2018, a Secretaria do Trabalho e Assistência Social do município de Cerro Largo/RS vem articulando parceria com Cooperativas de Crédito instaladas no município (SICREDI e CRESOL), para que contribuam com projetos oferecidos para público prioritário do Sistema Único de Assistência Social (SUAS). Um dos setores da Secretaria é o CRAS Cerro Azul, que tem como objetivo prevenir a ocorrência de situações de vulnerabilidade e riscos sociais nos territórios, por meio de desenvolvimento de potencialidades e aquisições, do fortalecimento de vínculos familiares e comunitários, e da ampliação do acesso aos direitos de cidadania. É exatamente o público atendido pelo CRAS, normalmente usuários do SUAS que são beneficiados com diferentes projetos e/ou programas.

Dentre os serviços prestados, podemos citar: Serviço de Proteção e Atenção Integral à Família (PAIF) cuja finalidade é fortalecer a função protetiva das famílias, prevenir a ruptura de seus vínculos e a violência no âmbito de suas relações, garantindo o direito à convivência familiar e comunitária; Serviço de Convivência e Fortalecimento de Vínculos (SCFV) com caráter preventivo e proativo, realizado em grupos, de modo a garantir aquisições progressivas aos seus usuários, de acordo com seu ciclo de vida. Destina-se a crianças, adolescentes, idosos em situação de vulnerabilidade e o Serviço de Proteção Social Básica em Domicílio para Pessoas com Deficiência e Idosas. Este tem a finalidade de prevenir os agravos que possam provocar o rompimento de vínculos familiares e sociais dos usuários.

De acordo com a Política Nacional de Assistência Social (PNAS) e o Ministério do Desenvolvimento Social e Combate à Fome, é interessante ressaltar que o CRAS deve desenvolver serviços socioassistenciais de inclusão produtiva e oferecer um suporte aos projetos de geração de renda existentes nos municípios.

Dentro dos Grupos do PAIF e SCFV, a Secretaria Municipal do Trabalho e Assistência Social por meio do CRAS Cerro Azul, desenvolve projetos pelos quais são oferecidas oficinas de modalidades e objetivos que têm como uma das preocupações o incentivo à geração de renda. Pensando nesse fator, no decorrer do ano de 2018, buscou diversas parcerias, podendo citar as Cooperativas de Crédito, 
SICREDI e CRESOL, que colaboraram com projetos do PAIF e SCFV, e visam também geração de renda para as famílias.

Por exemplo, no ano de 2018, a Unidade da Cooperativa de Crédito SICREDI auxiliou financeiramente nos cursos do SENAR, e aqui pode ser citado o Curso de Eletricista Básico Rural e Montador de Motor Elétrico, Curso de Jardinagem e Plantas em Vaso, Curso de Culinária (doces e salgados), dentre outros. 0 referido auxílio proporcionou a compra de alimentos (lanche e almoço) para serem oferecidos aos diversos grupos durante os dias de curso.

No ano (2019), a Secretaria Municipal do Trabalho e Assistência Social (SMTAS) e SICREDI novamente firmaram parceria referente a auxílio financeiro como complemento nos Projetos Sociais desenvolvidos no CRAS, disponibilizando também oficinas socioeducativas. Neste ano (2019), a SICREDI colaborará no Projeto Gestante Consciente (CRAS e Secretaria da Saúde), doando 25 (vinte e cinco) banheiras, que farão parte do enxoval das participantes. Além disso, também disponibilizará auxílio em outros cursos e projetos oferecidos no CRAS, em especial aos oriundos do SENAR que necessitarem de apoio financeiro, e ainda oportunizará oficinas que visam desenvolver práticas de ensino-aprendizado com foco na educação cooperativa de jovens e adolescentes, as quais serão proporcionadas por funcionários da Cooperativa.

Outra beneficiária é a Cooperativa de Trabalho de Catadores Unidos pela Natureza (COOPERCAUN), a qual foi fundada em 13 de dezembro de 2016, conta com a sede administrativa na Linha Primeira do município de Cerro Largo/RS. Destaca-se que a cooperativa foi constituída com o assessoramento da Incubadora Tecnossocial de Cooperativas e Empreendimentos Solidários (ITCEES), da Universidade Federal da Fronteira Sul (UFFS). O objetivo dessa cooperativa é proporcionar aos cooperados postos de trabalho mediante o esforço pessoal direto e aprimorar as atividades profissionais por meio da organização conjunta, atuando na coleta, triagem e reciclagem de resíduos sólidos. Além disso, a COOPERCAUN é responsável por triar os Resíduos Sólidos Urbanos (RSU) do município de Cerro Largo/RS, atendendo à Política Nacional de Resíduos Sólidos (PNRS) instituído pela Lei Federal no 12.305/2010.

A COOPERCAUN foi contemplada no ano de 2018 pela CRESOL, por meio do Projeto "Fortalecendo Vínculos e Ampliando Possibilidades", que teve como colaboradores, CRAS, ITCEES, UFFS, Superintendência dos Serviços Penitenciários (SUSEPE), Empresa de Assistência Técnica e Extensão Rural (EMATER) e a Secretaria da Agricultura. Esse projeto objetivou o atendimento e acompanhamento social da cooperativa com vistas a seu fortalecimento enquanto equipe de trabalho cooperativo, bem como capacitar os integrantes da COOPERCAUN por meio de oficinas socioeducativas acerca de temas centrais sobre trabalho em equipe, trabalho cooperativo, liderança, mediação de conflitos, autoestima e motivação para o trabalho e também visou a melhorias do ambiente onde está instalada a cooperativa.

Foi nessa etapa que a CRESOL colaborou financeiramente com materiais necessários para realização das oficinas práticas de jardinagem, hortas, e benfeitorias dentro do espaço físico da Cooperativa, de forma a contribuir para a funcionalidade do paisagismo dela, levando em consideração que essa etapa do projeto não poderia ser proporcionada financeiramente com valores oriundos da Secretaria Municipal do Trabalho e Assistência Social.

Por outro lado, a Cooperativa SICREDI contemplou a COOPERCAUN, no ano de 2018, por meio do fundo social no valor de $\mathrm{R} \$ 4.500,00$ para a aquisição de uma balança digital de $500 \mathrm{~kg}$, um computador de mesa e uma impressora, tudo com o propósito de otimizar os processos de trabalho da Cooperativa. 
Também em 2018 a CRESOL destinou o fundo social, para a programação natalina, colaborando de forma especial para o encerramento do ano com uma ação solidária distribuindo cupons de sorteio de um tablet e um patinete prioritariamente para grupos participantes de projetos do CRAS, usuários do Sistema Único de Assistência Social (SUAS), que possuem Número de Identificação Social (NIS), COOPERCAUN, escolas (ensino fundamental) estaduais e municipais de Cerro Largo/RS. Nessa mesma ação, a empresa colaborou de forma calorosa quando os próprios funcionários da CRESOL, voluntariamente, distribuíram 500 picolés.

Diante da apresentação dos resultados, constatou-se que, após experiências de parceria do CRAS e referidas cooperativas de Crédito, foi possível perceber que elas visam ao desenvolvimento social e econômico do município, além de demonstrar interesse na melhoria da qualidade de vida dos associados, bem como da comunidade em geral.

Assim a SICREDI e CRESOL são cooperativas comprometidas com o crescimento dos seus associados e com o desenvolvimento das regiões onde atuam. E, por esse motivo, a cada ano surgem novas ideias de buscar parceiros com os mesmos objetivos, que são a geração de renda e igualdade social.

A partir deste artigo, foi possível entender a importância do trabalho realizado por ambas as cooperativas no sentido de incentivo à geração e/ou complemento na renda das famílias usuárias do SUAS, bem como a possibilidade de inclusão social. Como se pode perceber, muitas das ações desenvolvidas pelas cooperativas SICREDI e CRESOL, foram "bem-vindas" como colaboradoras de projetos do CRAS Cerro Azul, pois estiveram relacionadas ao público prioritário.

\section{Considerações Finais}

o Centro de Referência de Assistência Social (CRAS) Cerro Azul do município de Cerro Largo/RS é um espaço que tem como objetivo atender o público-alvo. As Secretarias de Assistência Social, por meio dos recursos oriundos do Governo Federal e Estadual, destinados aos municípios, incluem referido público em projetos sociais.

Para melhores resultados, buscaram-se parcerias com a intenção de que estas possam contribuir de forma financeira e social com os projetos, já que estes objetivam principalmente a geração/complemento de renda. Com a contribuição das Cooperativas de Crédito CRESOL e SICREDI, foi possível realizar um trabalho que proporcionou resultados satisfatórios, tendo em vista a experiência que o CRAS adquiriu ao longo do ano de 2019.

Ficou evidenciado que ambas as cooperativas colaboram, seja com recursos financeiros ou com apoio e parceria em ações e/ou projetos, beneficiando o público alvo contido pelo CRAS. Destaca-se a colaboração com auxílios financeiros para realizar os cursos ofertados pelo SENAR, tais como curso de eletricista básico rural e montador de motor elétrico, curso de jardinagem e plantas em vaso e curso de culinária, com o projeto "gestante consciente", doando banheiras, e com o fundo social viabilizando a aquisição de equipamentos para a entidade cadastrada.

Dessa forma, as Cooperativas CRESOL e SICREDI atendem ao sétimo princípio do cooperativismo, que é interesse pela comunidade, ou seja, contribuem para o desenvolvimento sustentável de suas comunidades por meio de políticas aprovadas por seus associados. Desse modo, Dumond (2010) salienta que esse ramo do cooperativismo proporciona um forte apelo social e devem 
visar ao benefício não apenas de seus donos, que são todos os cooperados, mas de todo o meio social onde estão inseridas.

O cooperativismo, em um contexto geral, está intimamente ligado à história do desenvolvimento das várias regiões onde está fortemente presente. No contexto da modernidade e das relações contemporâneas, em que a economia colaborativa se destaca, as novas formas de organização cooperativa estão se movendo mais diretamente nas relações sociais e não apenas interagindo nas atividades de produção.

Por fim, tentou-se destacar uma agenda de pesquisa interessante para contribuir a compreensões e debates. Convém destacar outras sugestões de pesquisa, no sentido de desvendar diferentes experiências com entidades que repercutam no desenvolvimento do local de atuação, assim como descrever sobre economia solidária, cooperativismo e exclusão social, os quais carecem de sustentação para fortalecer possibilidades de melhorias à sociedade.

\section{Referências}

ALEIXO, Andreia Duarte et al. O cooperativismo de crédito: estratégias de fidelização dos cooperados para sustentação do negócio rural. In: XXXV Encontro Nacional de Engenharia de Produção, 35., Fortaleza. Anais. Fortaleza: Enegep, 2015. p. 1 - 15. Disponível em: https://www.google.com/url?sa=t\&rct=j\&q=\&esrc=s\&source=web\&cd=1\&cad=rja\&uact=8\&ved=2ah UKEwjM-

5nz2bvmAhV9JrkGHT7FB64QFjAAegQIBBAC\&url=http\%3A\%2F\%2Fwww.abepro.org.br\%2Fbibliotec a\%2FTN_STO_208_236_27831.pdf\&usg=AOvVaw0t2pfodZcUP30nJr_d6S8. Acesso em: 12 dez., 2019.

BÜTTENBENDER, Pedro Luís. Cooperativismo na Região Nordeste do Rio Grande do Sul: experiências de gestão cooperativa e de promoção do desenvolvimento. Porto Alegre/RS: Editora Sescoop/RS, 2010.

BRASIL. Ministério do Desenvolvimento Social e Combate à Fome. Política Nacional de Assistência Social. Brasília: MDSCF, 2004.

BRASIL. Constituição 1988. Constituição da República Federativa do Brasil. São Paulo: Atlas, 1988. Disponível em: http://www.planalto.gov.br/ccivil_03/constituicao/constituicao.htm. Acesso em: 16 dez. 2019.

BRESSER-PEREIRA, Luiz Carlos. O conceito histórico de desenvolvimento econômico. 2006. Disponível em: http://bibliotecadigital.fgv.br/dspace/handle/10438/1973. Acesso em: 10 dez. 2019.

CRESOL. Cresol Central. 2019. Disponível em: http://www.cresolcentral.com.br/a-cresolcentral>. Acesso em: 9 dez. 2019.

CRUZIÓ, Helnon de Oliveira. Como organizar e administrar uma cooperativa: uma alternativa para o desemprego. 4. ed. Rio de Janeiro: FGV, 2005. Disponível em: https://books.google.com.br/books?id=5RWHCgAAQBAJ\&pg=PT2\&lpg=PT2\&dq=CRUZIO+Como+org anizar+e+administrar+uma+cooperativa:+uma+alternativa+para+o+desemprego.\&source=bl\&ots=UB yNxa9B70\&sig=ACfU3U3KzHfSZ6FJC0QMaBDMQ8CfM_Ajg\&hl=ptBR\&sa=X\&ved=2ahUKEwj9qYqS27v mAhXSGLkGHRH2CB8Q6AEwBHoECAgQAQ\#v=onepage\&q=CRUZIO\%20Como\%20organizar\%20e\%2 0administrar\%20uma\%20cooperativa\%3A\%20uma\%20alternativa\%20para\%20o\%20desemprego.\& $\mathrm{f}=$ false. Acesso em: $12 \mathrm{dez} .2019$.

DE OLIVEIRA, Gilson Batista. Uma discussão sobre o conceito de desenvolvimento. Revista da FAE, v. 5, n. 2.2002 .2 Disponível em: https://www.google.com/url?sa=t\&rct=j\&q=\&esrc=s\&source=web\&cd=1\&cad=rja\&uact=8\&ved=2ah UKEwjRsZ2h9rnAhW4IrkGHR73D_gQFjAAegQIAxAB\&url=https\%3A\%2F\%2Frevistafae.fae.edu\%2Fre vistafae\%2Farticle\%2Fview\%2F477\&usg=AOvVaw2GsSZFlxLD-ngxTZQsfW5q. Acesso em 17 fev. 2020. 
DUMOND, V.R.S. A aplicação dos princípios cooperativistas na gestão dos empreendimentos cooperativos. Coletânea de artigos apresentados no I Encontro Brasileiro de Pesquisadores em Cooperativismo (EBPC). Brasília. 2010.

DUPAS, Gilberto. Economia global e exclusão social: pobreza, emprego, estado e o futuro do capitalismo. São Paulo: Paz e Terra. 1999.

ETGETO, Anderson Augusto et al. Os princípios do cooperativismo e as cooperativas de 55 crédito no Brasil. Maringa Management: revista de Ciências Empresariais, Maringá, v. 2, p.7-19, jan. 2005.

ELIAS, Norbert. Introdução à Sociologia. Lisboa. 70 ed. 1999.

GIL, Antônio Carlos. Como elaborar projetos de pesquisa. 4. ed. São Paulo: Atlas. 2002.

FÓRUM BRASILEIRO DE ECONOMIA SOLIDÁRIA (FBES). Carta de princípios da Economia Solidária. In: Plenária Nacional Da Economia Solidária, 3., Brasília, DF, 2006. Disponível em: https://www.google.com/url?sa=t\&rct=j\&q=\&esrc=s\&source=web\&cd=1\&ved=2ahUKEwjnyfq-

he3lAhVMDrkGHW2FBKMQFjAAegQIBRAC\&url=http\%3A\%2F\%2Fwww.mobilizadores.org.br\%2Fwp content\%2Fuploads\%2F2014\%2F05\%2Ftexto5363c725c2c79.pdf\&usg=AOvVaw0C2IDSIaUQXfsq297 IM8n. Acesso em: 15 dez. 2019.

FRANTZ, Walter. Associativismo, cooperativismo e Economia Solidária. Ijuí: Ed. Unijuí, p. 162. 2012.

FUNDAÇÃO SICREDI. A Trajetória do Sicredi: uma história de cooperação. Porto Alegre. Fundação Sicredi. 2014.

FURTADO, Celso. Prefácio à nova economia política. Rio de Janeiro: Paz e Terra, 1977.

IBGE, Instituto Brasileiro de Geografia e Estatística. Programa nacional de amostragem domiciliar, Brasil. 2013.

IBGE, Instituto Brasileiro de Geografia e Estatística. Histórico Cerro Largo. 2013. Disponível em: https://cidades.ibge.gov.br/brasil/rs/cerro-largo/historico. Acesso em: 11 dez. 2019.

KEIL, Ivete Manetzeder \& MONTEIRO, Silvio Tavares. Os pioneiros de Rochdale e as distorções do cooperativismo na América Latina. 1982.

Disponível em: http://livrozilla.com/doc/604466/os-pioneiros-de-rochdale-e-asdistor\%C3\%A7\%C3\%B5es. Acesso: 14 dez. 2019.KLAES, Luiz Salgado. Introdução ao Cooperativismo: livro didático. Palhoça: Unisul Virtual, 2006.172p.

LEI no 2.711, DE 21 DE SETEMBRO DE 2017. Lei Municipal Cerro Largo. Disponível em: https://www.lexml.gov.br/urn/urn:lex:br;rio.grande.sul;cerro.largo:municipal:lei:2017-09-21;2711. Acesso em: 12 dez. 2019.

LOURENÇO, Maria dos Prazeres. Pobreza e exclusão social e políticas sociais em Portugal. Uma análise de políticas sociais na relação com a pobreza. Lisboa: Direção Geral de Segurança Social. 2005.

MASY, Rafael Carbonell de Estrategia de desarrollo rural en los pueblos guaraníes (1609-1767). Barcelona. Instituto de Cooperación Iberoamericana E.A. Bosch. 1992.

MATTAR, Fauze Najib. Pesquisa de marketing. 6. ed. São Paulo: Atlas. 2005.

MINISTÉRIO DO TRABALHO E EMPREGO (2014). Disponível em: http://portal.mte.gov.br/ecosolidaria/o-que-e-economia-solidaria.htm. Acesso em: 11 dez. de 2019.

OCB - Organização das Cooperativas do Brasil. Cresce número de pessoas ligadas ao Cooperativismo. Disponível em: https://www.ocb.org.br/. Acesso em: 30 dez. 2019. 
PEDRINI, D. M.; OLIVEIRA, A. L. A economia solidária como estratégia de desenvolvimento. Emancipação, v. 7, n. 1, p.111-133, 2007.

PLATAFORMA AGENDA 2030. Disponível em: http://www.agenda2030.com.br/sobre/. Acesso em: 17 fev. 2020.

PINHEIRO, M. A. H. Cooperativas de Créditos: história e evolução normativa no Brasil. 6. ed. Brasília: BCB, 2008.

RIGO, A. S.; SILVA JÚNIOR, J. T.; SCHOMMER, P. C.; CANÇADO, A. C. Gestão Social e Políticas Públicas de Desenvolvimento: Ações, Articulações e Agenda. Recife: UNIVASF, 2010.

ROCKENBACH, Cleoci Werle. Estudo sobre a execução da política de assistência social em municípios da região das Missões: uma análise à luz dos valores do humanismo. 2017. Disponível em: https://rd.uffs.edu.br/handle/prefix/1673. Acesso em: 12 dez. 2019.

SACHS, Ignacy. Estratégias de Transição para do século XXI - Desenvolvimento e Meio Ambiente. São Paulo: Studio Nobel - Fundação para o desenvolvimento administrativo. 1993.

SANTANA, Fernando de Souza. Cooperativas de Crédito: Agentes de Desenvolvimento Local - um estudo de caso. Faculdades Sudamérica, v. 2. 2010.

SANTOS, B. S. Produzir para viver: os caminhos da produção não capitalista. 3. ed. Rio de Janeiro: Civilização Brasileira, 2012.514 p.

SCHMIDT, D.; PERIUS, V. Cooperativismo - cooperativa. In: CATTANI, Antonio David (Org.). A outra economia. Porto Alegre: Veraz Editores, p. 63-71. 2003.

SESCOOP. Serviço Nacional de Aprendizagem do Cooperativismo do Estado do Rio Grande Do Sul. 2019. Disponível em: www.ocb.sescoop.br . Acesso em: 10 dez. 2019.

SILVA, José Luís Alves da. A economia solidária como base do desenvolvimento local. e-cadernos CES, n. 02. 2008.

SINGER, Paul. Introdução à economia solidária. Fundação Perseu Abramo. 2002.

SINGER, P.; SOUZA, A. R. (org.). A economia solidária no Brasil: a autogestão como res-posta ao desemprego. São Paulo: Contexto, 2000.

TAVARES, Arlindo Semedo. Pobreza, exclusão social e desenvolvimento social: o caso do programa rede social em Almada. 2013. Disponível em: https://repositorio.iscteiul.pt/handle/10071/8358. Acesso em: 11 dez. 2019.

TÉCNICAS, Orientações. Centro de Referência de Assistência Social (CRAS). Ministério do Desenvolvimento Social e Combate à Fome. Brasília. 2009.

TORRAS, Marta; ALMANSA, Fernando. La participación de los pueblos en su desarrollo. Intermón. 1995.

UNISOL BRASIL. 0 que é a Economia Solidária? Disponível em: http://www.unisolbrasil.org.br/oque-e-economia-solidaria/. Acesso em: 30 dez. 2019. 